Reseña bibliográfica

\title{
El desarrollo psicológico no es lo que parece
}

\author{
Jean Nikola Cudina*
}

Puche, R. (Comp.). (2017). El desarrollo cognitivo se reorganiza. Emergencia, cambio, autorregulación y metáforas visuales. Colombia: Editorial Bonaventuriana/ Universidad Autónoma de Occidente/California-edit.

"El desarrollo cognitivo se reorganiza" es un libro provocador que pretende seducir el pensamiento del psicólogo interesado en el proceso del desarrollo cognitivo del niño. En este libro el psicólogo tradicionalista, acostumbrado a la comodidad de los manuales, se encontrará con una contrariedad que puede causar desazón: no hay leyes que definan el desarrollo, ni mucho menos una ley general que sincretice el desarrollo en una escala de tiempo marcada por capacidades o competencias.

La psicología del desarrollo se ha pensado, durante muchos años, como un proceso lineal que implica atravesar por una serie de estadios o etapas inflexibles y escalonadas del desarrollo esperado. Sin embargo, esta concepción ha sido objeto de críticas, pues se ha evidenciado una debilidad ontológica en los estudios de la psicología del desarrollo como disciplina.

Contrario a dicha perspectiva, en esta obra se descubren las bases teóricas, conceptuales y metodológicas que fundamentan, en esencia, la perspectiva de una nueva psicología del desarrollo, ya que en el transcurso de los cuatro capítulos se discute el objetivo de lograr un punto de encuentro entre los sistemas dinámicos no lineales y la psicología del desarrollo inscrita en una concepción vanguardista que ha logrado trascender el debate epistemológico, ontológico y metodológico clásico.

Alo largo del libro se presentan argumentos y evidencias empíricas que develan la crisis paulatina de la teoría clásica de la psicología del desarrollo, puesto que el alcance teórico de esta implica una imposibilidad para integrar observaciones cada vez más centrales. Esto determina el surgimiento de lo que Thomas Kuhn (1971) denomina como "revolución científica" (p. 75), ya que todo progreso importante del conocimiento opera necesariamente por la quiebra y la ruptura de sistemas cerrados que no tienen dentro de ellos mismos la aptitud de la trascendencia.

La posibilidad de reorganizar los principios ontológicos y los elementos epistemológicos que envuelven los estudios de la psicología del desarrollo se encuentran consignados en este libro. Específicamente, se consideran como objeto de estudio los complejos mecanismos responsables de los cambios que subyacen a las trayectorias del desarrollo infantil y que ejercen un rol importante al permitir la visualización de movimientos, transformaciones y procesos de cambio en el mismo.

Esta organización ontológica reposa en el rigoroso corpus que subyace al interior de la teoría de los sistemas complejos y que desemboca con las lógicas consecuentes de los llamados sistemas dinámicos. Su fundamentación teórica obliga a concebir al desarrollo como un sistema abierto, dinámico y complejo en el que cada componente de análisis se encuentra intrínsecamente relacionado con otro. Concepción que resulta de una revuelta epistémica que conlleva a pensarse al desarrollo desde otra perspectiva pertinente que posibilita la emergencia de nuevos saberes en el fortalecimiento tanto de la teoría como de la práctica en esta ciencia.

Por otra parte, resulta imprescindible la búsqueda rigurosa y el afianzamiento de los diseños metodológicos consecuentes al cambio suscitado por la conceptualización de una psicología del desarrollo en el marco de los sistemas dinámicos no lineales. Según esto, es necesario ajustar los diseños según la demanda exigida por los procesos de transformación en el desarrollo del infante, tal como se ha hecho en las adaptaciones del método microgenético que se han venido desarrollando en el grupo de investigación Cognición $y$ desarrollo representacional del Centro de Investigaciones en Psicología, Cognición y Cultura de la Universidad del Valle de Cali, con las cuales es posible realizar un registro de la actividad del niño frente a una situación de resolución de problemas que permite representar-dentro de la lógica de los sistemas dinámicos no lineales- las movilizaciones

\footnotetext{
* Universidad de San Buenaventura, Facultad de Psicología, seccional Cali,jncudina@usbcali.edu.co,j.nikolacudina@hotmail.com
} 
de cada uno de los avances y retrocesos en la trayectoria de su desarrollo.

El afianzamiento metodológico (figura) y las bases teóricas y conceptuales que se definen en los estudios del desarrollo (fondo) se entrelazan a través de los sistemas dinámicos no lineales y se convierten en el tejido base del modelo que busca la comprensión del desarrollo centrado en el sujeto y que apunta a una apertura epistémica que incita a una superación del conocimiento. El rigor epistemológico que constituye esta obra rompe con cualquier indicio estratégico que desemboque en el control soberano del conocimiento; y en estos términos, esta obra representa la entrada a un campo de la psicología que se replantea sus fundamentos teóricos y conceptuales, de acuerdo con las exigencias y demandas que surgen del desarrollo de la ciencia y que permiten vislumbrar un terreno lleno de precedentes.

Así, este libro otorga una invitación a que la investigación de la psicología del desarrollo se fortalezca y enriquezca, ya que en la actualidad hay una ausencia de estudios -en Colombia- que planteen una problematización desde la perspectiva de los sistemas dinámicos no lineales (Cudina \& Ossa, 2016), y dado que los que hay resultan cada vez más débiles metodológicamente y más estrechos conceptual y epistemológicamente. De este modo, las ideas en el área parecen agotadas y desde hace mucho tiempo este desgaste se refleja en los pénsums de las facultades de psicología colombianas, que siguen enseñando una psicología del desarrollo manualista y poco progresista. En este sentido, este libro se constituye como una referencia obligada para los programas de formación académica de los psicólogos y psicólogas en Colombia.

La psicología requiere de un impulso fundamental para el avance de los diversos saberes que se gestan al interior de la psicología del desarrollo contemporánea. Puede decirse que este libro deja caer una manzana para que el psicólogo tradicionalista le dé una fuerte mordida.

\section{REFERENCIAS}

Cudina, J. N., \& Ossa, J. C. (2016). The top 100 high-impact papers in Colombian psychology: a bibliometric study from WoS and Scopus. Informação \& Sociedade: Estudos, 26(2), 137-154.

Kuhn, T. (1971). La estructura de las revoluciones cientificas. México: Fondo de Cultura Económica.. 